\title{
Coral reef fish communities, diversity, and their fisheries and biodiversity status in East Africa
}

\author{
Timothy R. McClanahan \\ Wildlife Conservation Society, Marine Programs, Bronx, New York, NY 10460, USA
}

\begin{abstract}
Coral reef fish along the East African coast were evaluated for the distinctiveness of their communities, their distributions and interactions with the environment, and their responses to management. I studied the biomass and species richness of 24 fish families at 238 unique sites in Kenya, Tanzania, and Mozambique. I identified an unfished benchmark that was associated with high biomass, high-compliance closures or low access to fishing along with 6 additional statistically different communities. In the benchmark community, biomass was dominated by snappers, surgeonfish, parrotfish, and wrasses. Of the 24 families studied, 11 declined relative to the benchmark community, with the greatest declines observed among surgeonfish, snappers, sweetlips (grunts), groupers, and triggerfish. I evaluated the community's spatial distributions and associations of 15 of 23 environmental and human-impact variables. Fish biomass was most positively influenced by the extent of shallow water $<50 \mathrm{~m}$ adjacent to the sites, depth, and high-compliance closures and negatively impacted by human populations within a $100 \mathrm{~km}$ radius of the site. Number of fish species was largely predicted by biomass with weak evidence for local environmental control. Classification of the biomass into 3 proposed management thresholds revealed that $~ 38 \%$ of the sites were below sustainable yields, $54 \%$ were below maximum species richness, and $92 \%$ below a proposed stable-ecosystem or conservation threshold. Therefore, increasing biomass of vulnerable taxa through fishing restrictions is recommended for maintaining sustainable fisheries, species diversity, and ecosystem services.
\end{abstract}

KEY WORDS: Biodiversity conservation - Ecosystem-based management - Gear restriction · Functional ecology $\cdot$ Indian Ocean $\cdot$ Marine reserves $\cdot$ Sustainability

\section{INTRODUCTION}

Coral reef fish communities are structured by a variety of historical, environmental, ecological, and human influences (Mellin et al. 2014, Pellissier et al. 2014, MacNeil et al. 2015, 2016). The roles that these forces play in influencing community composition, biomass, diversity, and ecological function are increasingly being understood on large regional and global scales (Parravicini et al. 2013, McClanahan 2015, Williams \& Graham 2019). Biomass and diversity of fishes are among the key metrics that influence the maintenance of reef structure, processes, and fish-

${ }^{*}$ Corresponding author: tmcclanahan@wcs.org eries production (Thibaut \& Connolly 2013, Pratchett et al. 2014, Lefcheck et al. 2019). Therefore, studies that evaluate these metrics are expected to provide insights into the state and management of fisheries needed to maintain reef ecosystem services (Parravicini et al. 2014, Mouillot et al. 2016). These evaluations are most useful if their status can be compared to known baselines, benchmarks, and thresholds of production and ecological change (MacNeil et al. 2015, Gorospe et al. 2018).

Prior work has established that reef functions, such as calcification and fisheries production, are influenced by energetic and consumption processes that

() The author 2019. Open Access under Creative Commons by Attribution Licence. Use, distribution and reproduction are unrestricted. Authors and original publication must be credited. 
are driven by reef fish metabolism (McClanahan et al. 2011, McClanahan 2018a, Bellwood et al. 2019). Therefore, managing the biomass of fish communities is a simple way to influence these ecosystem services and increase resilience to fishing and climate disturbances (Graham et al. 2017, Robinson et al. 2019). Many of the most detrimental changes to reef ecology occur when fish biomass declines below some fraction of an unfished biomass (McClanahan \& Muthiga 2016a,b). Unfished biomass studies indicate that biomass is influenced largely by human actions in the broader seascape (Cinner et al. 2018). Biomasses in remote and uninhabited seascapes are considerably higher than estimates from high-compliance closures in human-dominated seascapes (McClanahan et al. 2019). These have been referred to as baselines and benchmarks, respectively.

Total fish biomass has been a useful metric for evaluating multi-species status, but it is less useful for evaluating the composition of (and changes in) the fish community. Thus, while simplifying evaluations, it also limits understanding of the impacts of fishing on specific taxa and identifying those most susceptible to fishing or threatened by extirpation (Buckley et al. 2019). Changes in taxa along the biomass depletion continuum is less understood but it may be important for understanding the management needs of specific fish resources and changes in reef ecological processes. Moreover, if management is to be successful, it is important to understand the drivers of biomass (and its depletion) in order to prioritize management actions that are contextual, feasible, and cost effective. Assessments of status and services is particularly useful in regions where people are highly dependent on natural resources and remote baselines are uncommon, such as in East Africa (Hicks 2011, McClanahan et al. 2019).

I examined fish communities along the inhabited coastline of East Africa where fisheries closure benchmarks are few and are imbedded in human-dominated seascapes, and therefore the only means to assess regional status (Wells et al. 2007, McClanahan et al. 2009, 2015). My goal was to determine (1) if there are distinct coral reef fish communities at the family level, (2) communities that are representative of an unfished benchmark, (3) the main environmental, habitat, and human drivers of biomass and numbers of species, (4) how their distributions are influenced by fisheries management and access, and (5) the frequency of these communities relative to proposed regional yield, diversity, and conservation benchmarks or thresholds. From this assessment, I propose recommendations for management.

\section{MATERIALS AND METHODS}

\subsection{Study sites}

I examined coral reef fish communities, biomass, and diversity in 3 ecoregions (Spalding et al. 2007) and countries of the East African coastline $\left(\mathrm{EAC}_{\mathbf{i}}\right.$ Fig. 1), which lies within the social-political affiliation known as the Southwest Indian Ocean (SWIO). The EAC ecoregion extends across latitude $1.74^{\circ}-$ $22.04^{\circ} \mathrm{S}$ and longitude $35.52^{\circ}-41.53^{\circ} \mathrm{E}$, which provides a natural geographic and environmental latitudinal gradient (McClanahan \& Muthiga 2016a). The ecoregions surveyed were (from north to south) the Northern Monsoon Coast, East African Coral Coast, and Delagoa ecoregion (Spalding et al. 2007). Study sites were located on the windward and leeward sides of coral reefs in depths ranging from 1.5-20 m at low tide (the region's tidal range is $\sim 3-4 \mathrm{~m}$ ). Sites were all located on calcium carbonate dead coral bottoms colonized by hard and soft corals and various algae, with sand and seagrass being a smaller portion of the cover (McClanahan \& Muthiga 2016b).

\subsection{Fish censuses}

Between 2005 and 2017, I surveyed fish in $500 \mathrm{~m}^{2}$ belt transect replicates (1-9 site ${ }^{-1}$ ) using 2 methods (McClanahan \& Jadot 2017). During the first pass, I identified individual fish to 24 families and estimated their sizes, categorizing them into $10 \mathrm{~cm}$ size interval classes. During subsequent passes, I counted and identified individuals to species level in a smaller group of pre-selected families (marked with an asterisk in the following list). Fish families counted included Acanthuridae*, Aulostomidae, Balistidae*, Caesionidae, Carangidae, Chaetodontidae*, Diodontidae*, Fistularidae, Haemulidae, Holocentridae, Labridae*, Lethrinidae, Lutjanidae, Muraenidae, Mullidae, Pempheridae, Pinguipedidae, Pomacanthidae* ${ }^{*}$ Pomacentridae*, Scaridae*, Serranidae, Scorpaenidae, Siganidae, Sphyraenidae, and an 'others' category for individuals not in these families. The Monacanthidae ${ }^{*}$ were identified to species level but were placed in the 'others' category for biomass estimates. This second species richness method was used where time allowed for sampling, and therefore had a smaller sample size.

A goal of this study involved determining ecological roles, and therefore Scaridae and Labridae were treated as unique rather than subfamilies, as scarids are grazers/detritivores while labrids are carnivores (Westneat et al. 2005). I estimated the wet weight of 
each family by summing each size class based on established length-weight relationships (McClanahan \& Kaunda-Arara 1996). I used the sum of all size classes and families to estimate the total wet weight and then converted these values to units of $\mathrm{kg} \mathrm{ha}^{-1}$. Fish biomass was estimated for 4 categories: total, fishable, target, and non-target. Fishable biomass is the total biomass excluding the Pomacentridae and all fish $<10 \mathrm{~cm}$ in body size. Target was distinguished from nontarget biomass based on the family and size preferences of fishers in this region (described in McClanahan 2018a).

\subsection{Benthic cover and depth}

Benthic cover of hard and soft coral and erect algae were estimated in 15 haphazardly established $\sim 2 \mathrm{~m}^{2}$ visual quadrats adjacent to the fish census transects. All coral colonies $>5 \mathrm{~cm}$ were identified to 36 genera or subgenera, and their historical susceptibility to bleaching was used to calculate a weighted community susceptibility to thermal stress (McClanahan et al. 2007). I estimated the depth of each site using a depth gauge and a tape measure in shallow sites. The final set of benthic variables included depth, coral community susceptibility to thermal stress, number of coral taxa, hard coral, macroalgae, and soft coral cover.

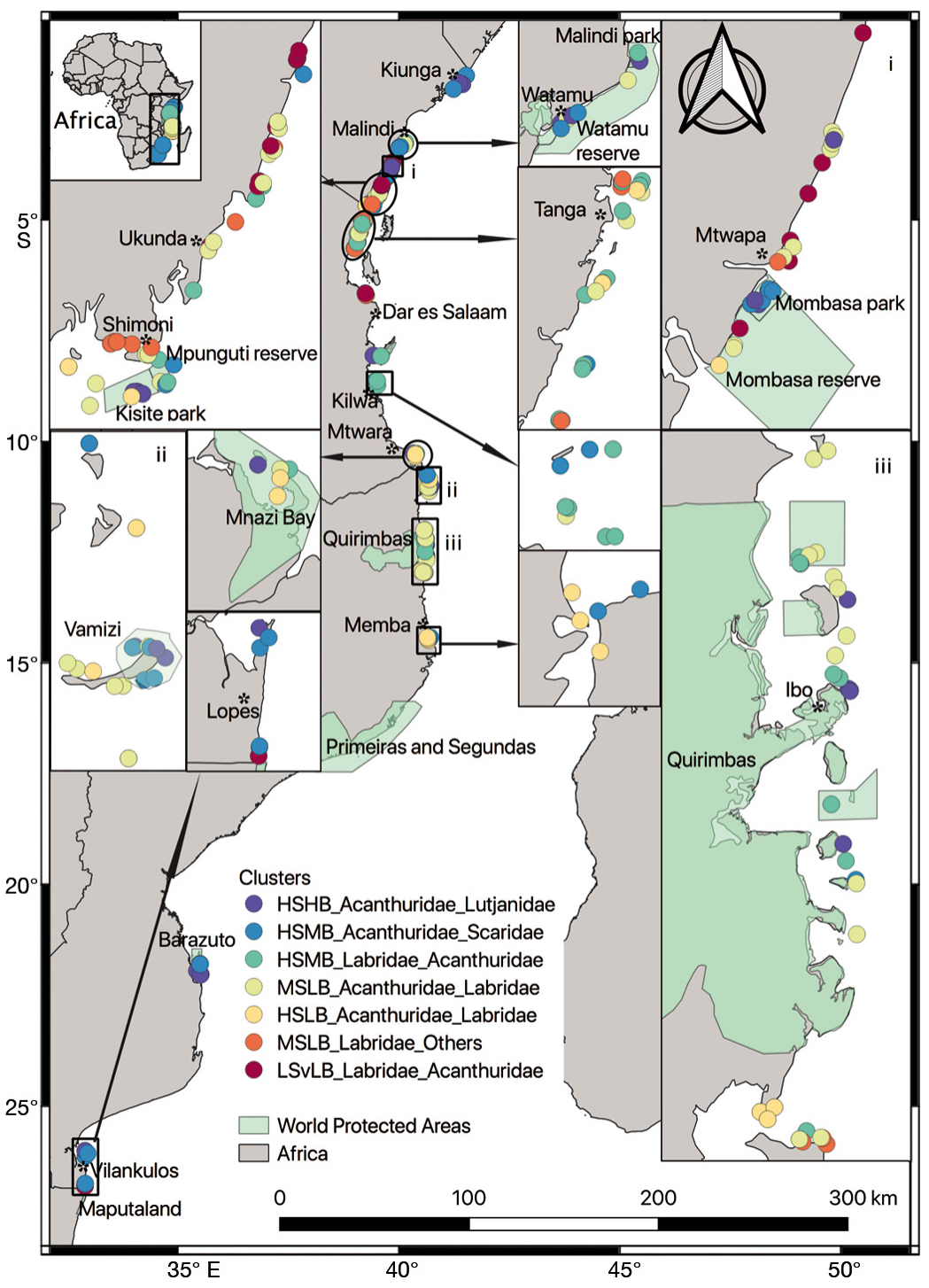

Fig. 1. Study sites along the East African coastline and distribution of the 7 fish family cluster groups, distributed from lowest (red) to highest biomass (blue) see Table 1 for description of cluster abbreviations

\subsection{Environmental variables}

I accessed sea surface temperature (SST) data from NOAA's Coral Reef Watch (CRW) database version 3.1 (https://coralreefwatch.noaa.gov/product $/ 5 \mathrm{~km} /$; collected daily at $5 \mathrm{~km}$ resolution) and summarized the mean, minimum, maximum, median and SD. Light $\left(\mathrm{mol} \mathrm{m}^{-2} \mathrm{~d}^{-1}\right)$ and 2 water quality variables, chlorophyll $a\left(\mathrm{chl} a_{i} \mathrm{mg} \mathrm{m}^{-3}\right.$ ) and the concentration of total suspended solids $\left(\mathrm{g} \mathrm{m}^{-3}\right)$, were obtained from the COASTCOLOUR project (www.coastcolour.org). The European Space Agency's GlobColor data were used rather than MODIS, SeaWIFS, or MERIS because it uses multiple sensors that average out errors from individual sensors, thus reducing overall data variability and uncertainties such as those caused by bottom reflectance. Water depth and distance from land were extracted from NOAA's bathymetric data using the function 'dist2isobath' in the R (v.1.0.2) package 'marmap' (Pante et al. 2018). I used data from 1985-2017, which included a total of 23 water quality, light, and SST-derived variables. Thermal stress anomalies (TSAs; defined as SST minus maximum of weekly mean climatological SST) was extracted from version 5 of the Coral Reef Temperature Anomaly Database (CoRTAD), which has a $4 \mathrm{~km}$ resolution for the period 1982-2012 (www.nodc. noaa.gov/SatelliteData/Cortad/) and summarized the mean, minimum, maximum, median, and SD. 


\subsection{Human influence proxies}

In total, 3 metrics were developed based on human population density and distance or travel time to the nearest population or city (Brewer et al. 2013, Maire et al. 2016). Population data were derived from the Marine Socio-Environmental Covariates (MSEC) data set (Yeager et. al. 2017). I used population data within a $100 \mathrm{~km}$ radius of the site for the year 2015, which was the most recent available estimate. Human influence was calculated with the following formula:

Human influence $=$
$\log _{e}\left(\frac{1+\text { human count within } 100 \mathrm{~km} \text { radius }}{(1+\text { distance of population to the reef })^{2}}\right)$

Additionally, 'gravity' as travel time to the nearest city or human population was calculated using the above formula but replacing the distance with the 2 travel time variables (Cinner et al. 2018). The travel time to to a human population sets a maximum distance at $500 \mathrm{~km}$. The nearest city is assumed to be the nearest major market for fish.

I derived the management categories from the fishing gears used at the time of the surveys. Management was broadly defined as (1) fished without gear restrictions, (2) fished but where some gears are restricted, (3) low compliance, and (4) high-compliance closures or reserves. The fished category included sites that had no enforced management and allowed fishing; the restricted category included sites that had implemented some gear restrictions - usually small mesh, drag nets, and spear-guns; low-compliance closures were legally gazetted or community agreed-on notake zones that were either small $\left(<1 \mathrm{~km}^{2}\right)$ or poorly enforced; and high-compliance closures included notake sites that were regularly enforced, usually by the government but also with some private or strong community enforcement (i.e. Chumbe and Vamizi Islands). I categorized sites based on personal observations, scientific literature, and communications with experienced managers and scientists, not by their national legal status (McClanahan et al. 2015).

\subsection{Data analyses}

I collated the multiple sources of data, and evaluated and tested for similarities among sites, relationships between biomass, number of species, benthic cover, distance to deep water, depth, human influence, and satellite-based environmental data. Replication for these analyses differed because of differences in measurements or available data and, in some cases, pooling of nearby sites. Of the total of 354 time $\times$ site replicates, 353 had all environmental variables measured in the field. For some environmental analyses, replicates sampled in nearly the same place over time were pooled; this reduced the total number of replicates with biomass to 238 and the total with species to 217 sites.

In order to answer the questions on distinct and benchmark communities, I analyzed the biomass of the fish community using similarity and cluster analysis techniques. I performed a hierarchical cluster analysis on biomass values of 24 fish families and the 'others' group that pooled all other species. Site similarities were based on the Bray-Curtis similarity index and clustered using hierarchical Ward variance method in the R (v.3.2.3) package 'vegan'. I ran a similarity profile test (SIMPROF) that employs null hypothesis testing to detect statistically significant structure in ecological communities $(\mathrm{p}<0.05)$ with the $\mathrm{R}(\mathrm{v} .1 .1)$ package 'clustsig' (https://CRAN.R-project.org/package =clustsig) (Clarke et al. 2008). I performed the clustering methods using raw and $\log _{\mathrm{e}}$-transformed biomass; however, raw data are presented in the results.

Statistically significant fish cluster groups were given names based on 3 levels of species richness (LS: low; MS: moderate; HS: high), 4 levels of biomass (vLB: very low; LB: low; MB: moderate; HB: high), and the 2 most dominant fish families (see Table 1). Significant cluster groups were compared for differences in abundance of families and environmental and human influence variables using Kruskal-Wallis and/or ANOVA tests based on the normality of the data. The cluster with the highest biomass was considered the benchmark community for subsequent comparisons. Moran's I index was used to test for spatial autocorrelation and spatial clustering of biomass, number of species, and community composition based on the 2 community structure axes. I also used Moran's $I$ to test if distributions in space differed from random.

Fishable biomass and number of species were closely aligned with the cluster groups, and therefore I addressed the question of relationships between distributions and environmental and human drivers with satellite-derived environmental variables. First, I tested 23 potential variables for collinearity and variance inflation factors (VIF) and removed variables with high covariance and similarity. Secondly, variables were tested for fits to dependent variables (Fig. $\mathrm{S} 1$ in the Supplement at www.int-res.com/articles/ suppl/m632p175_supp.pdf). Finally, from these results, I choose 14 distinct variables for further analyses with biomass and number of species. The final satellite-derived variables included median photosynthetically 
active radiation (PAR), mean and median $\mathrm{chl} a$, and from the SST time-series, mean, minimum, maximum, median, bimodality, and SD of SST and TSA metrics. Other variables included depth, distance to land, distance to $50 \mathrm{~m}$ water depth (a measure of amount of shallow or deep water near the reef), management, satellitederived environmental variables, gravity to nearest market and population, and human influence. I also evaluated these variables by the same procedure and reduced them to 5. Lastly, I ran variable selection processes twice, both with and without covarying variables, but found no differences; therefore, I present the original variables that passed the covariance analysis.

I observed correlation matrices, and scatterplots of fish biomass-environmental data relationships were either linear or had non-significant relationships (Fig. S1). Relationships between environmental and number of species data were less clear and potentially unimodal (Clauson-Kaas et al. 2017). Consequently, I tested number of species for fits to both linear and second-order polynomial relationships but found (with a few exceptions) that linear fits were similar and all explained low $(<12.0 \%)$ amounts of variation (Table S1). The 3 exceptions I found were that polynomials fit number of species, distance to $50 \mathrm{~m}$ depth, and mean and median SST better than linear fits $\left(\mathrm{r}^{2}=0.10-0.15, \mathrm{p}<0.0001\right)$. However, the differences were small and unlikely to have large effects on linear model fits. Therefore, I examined a final set of 19 variables for relationships with biomass and number of species.

Subsequent analyses included multiple and stepwise linear regression analyses to evaluate overall fits to linear models, followed by boosted regression tree (BRT) analysis to evaluate explained deviance with non-linear and categorical variables, using the R package 'dismo' (https://CRAN.R-project.org/web/ packages/dismo/vignettes/brt). I considered BRT methods the best option for accounting for covariance, non-linearities, and interactions, and so the main analyses presented are the partial plots of environmental relationships (Elith et al. 2008). I excluded number of fish species when evaluating biomass to focus on the environmental influences independent of species richness. Nevertheless, I retained biomass when evaluating number of species, as it was the primary driver (McClanahan 2015).

Multivariate ordination of the sites and site descriptor variables were done in the R (v.2.4.2) package 'vegan', using canonical correspondence analysis (CCA) to evaluate the influence of environmental variables and habitat on fish family biomass. I included variables that were statistically significant based on forward stepwise regression procedures as vectors in the CCA. I excluded rare fish taxa contributing $<1 \%$ of the biomass (Aulostomidae, Diodontidae, Fistularidae, Muraenidae, Pempheridae, Penguipedidae, Scorpaenidae, Caesionidae, Lethrinidae and Sphyraenidae) to reduce their influence on the explained variance (Legendre \& Legendre 1998). I present 2 CCA analyses: one that evaluated the site's fish composition with respect to benthic cover and depth and the second with environmental variables, distance to shore and $50 \mathrm{~m}$ depth, gravity to nearest market and population, and latitude. I produced scatterplots of the environmental and human influence variables versus latitude, biomass, and number of species.

The frequency of sites relative to the total number of sites was calculated as the percentage of sites below the yield, diversity, and conservation thresholds. I classified sites by the 4 fisheries management and 7 significant community structure categories using criteria established in previous regional evaluations. For example, a compilation of many field studies indicated that reef communities undergo more ecological change when biomass is $<1150 \mathrm{~kg} \mathrm{ha}^{-1}$ (2 SD above the mean threshold) (McClanahan et al. 2011). Thus, this value was established as an ecological 'conservation threshold'. Biomass recovery and yield studies have established a sustainable yield level of $\sim 6 \mathrm{t} \mathrm{km}^{-2} \mathrm{yr}^{-1}$, estimated to occur between 450 and $600 \mathrm{~kg} \mathrm{ha}^{-1}$ (McClanahan 2018b). Thus, this $450 \mathrm{~kg} \mathrm{ha}^{-1}$ minimum provided an estimate of reefs above or within sustainable yield levels. Finally, above a mean biomass of $\sim 600 \mathrm{~kg} \mathrm{ha}^{-1}$ the number of fish species does not increase, thus establishing a diversity categorization for sites above and below this threshold (McClanahan 2015). This diversity threshold is similar to a $\sim 650 \mathrm{~kg}$ $\mathrm{ha}^{-1}$ value previously established for maintaining reef fish trophic structure (Graham et al. 2017). Finally, I used the highest biomass cluster as a benchmark to visualize changes in fishable biomass of the other 6 clusters at the family level.

\section{RESULTS}

\subsection{Fish community attributes}

SIMPROF identified 7 significantly different clusters (Tables $1 \&$ S2). These family-based clusters closely aligned with mean biomass and number of species (Fig. 2a,b). I named the clusters using combinations of 3 statistically significant categories for biomass and 4 categories for number of species. Consequently, community similarity clusters were arranged 

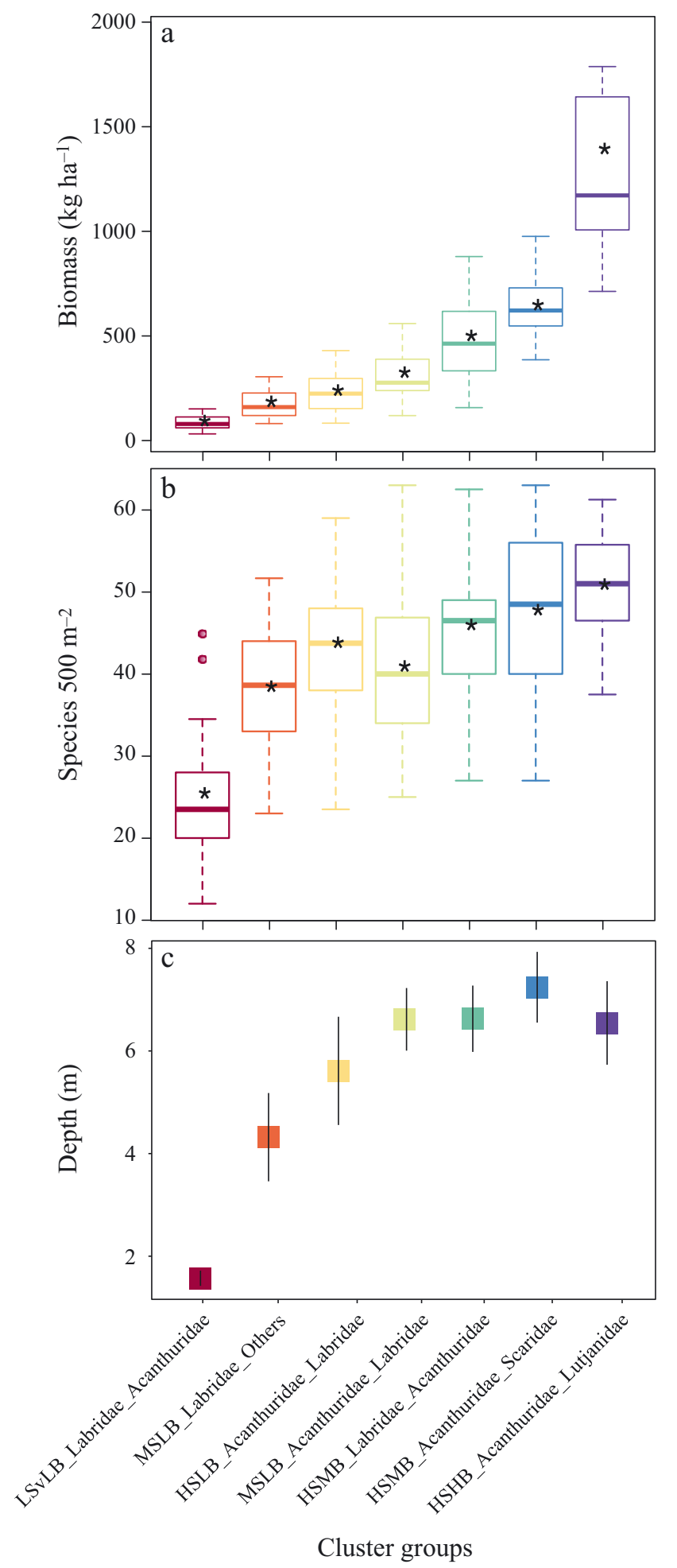

Fig. 2. Relationships between the 7 fish family cluster groups and their (a) biomass, (b) number of species in 9 common families per $500 \mathrm{~m}^{2}$, and (c) depth. Black asterisks: mean values for each category; thick bars: medians; boxes: interquartile range (IQR); whiskers: min./max. values $<1.5 . \times \mathrm{IQR}_{\text {; }}$ colored circles: outliers. Whiskers in (c): SE. See Table 1 for description of cluster abbreviations
Table 1. Definitions, criteria, and abbreviations of cluster categories identified in coral reef fish communities along the African coastline. Mean \pm SE of dominant fish families presented for each cluster group. Detailed descriptions of evaluated metrics for each cluster are summarized in Table 2. Cluster abbreviations: LS: low species $\left(<39\right.$ per $\left.500 \mathrm{~m}^{2}\right)$; MS: moderate species $\left(39-41\right.$ per $500 \mathrm{~m}^{2}$; HS: high species (>41 per $\left.500 \mathrm{~m}^{2}\right)$; vLB: very low biomass $\left(<170 \mathrm{~kg} \mathrm{ha}^{-1}\right)$; LB: low biomass $\left(170-300 \mathrm{~kg} \mathrm{ha}^{-1}\right)$; MB: moderate biomass (300$700 \mathrm{~kg} \mathrm{ha}^{-1}$ ); HB: high biomass (>700 kg ha ${ }^{-1}$ ). The last column represents the biomass of the top 14 dominant fish taxa in each cluster

\begin{tabular}{|c|c|c|c|}
\hline $\begin{array}{l}\text { Cluster } \\
\text { no. }\end{array}$ & $\begin{array}{l}\text { Cluster name } \\
\text { abbreviation }\end{array}$ & $\begin{array}{l}\text { No. of sites } \\
\text { cluster }^{-1}\end{array}$ & $\begin{array}{l}\text { Biomass of } \\
\text { fish families }\end{array}$ \\
\hline 1 & $\begin{array}{c}\text { LSvLB_Labridae } \\
\text { _Acanthuridae }\end{array}$ & 21 & $94.29 \pm 7.73$ \\
\hline 2 & $\begin{array}{l}\text { MSLB_Labridae } \\
\text { _Others }\end{array}$ & 20 & $203.03 \pm 15.33$ \\
\hline 3 & $\begin{array}{l}\text { HSLB_Acanthuridae } \\
\text { _Labridae }\end{array}$ & 23 & $328.97 \pm 15.62$ \\
\hline 4 & $\begin{array}{c}\text { MSLB_Acanthuridae } \\
\text { _Labridae }\end{array}$ & 53 & $319.99 \pm 17.03$ \\
\hline 5 & $\begin{array}{l}\text { HSMB_Labridae } \\
\text { _Acanthuridae }\end{array}$ & 48 & $519.58 \pm 31.00$ \\
\hline 6 & $\begin{array}{c}\text { HSMB_Acanthuridae } \\
\text { _Scaridae }\end{array}$ & 36 & $650.36 \pm 19.63$ \\
\hline 7 & $\begin{array}{c}\text { HSHB_Acanthuridae } \\
\text { _Lutjanidae }\end{array}$ & 37 & $1372.90 \pm 90.45$ \\
\hline
\end{tabular}

and numbered from 1-7 from lowest to highest biomass. Only 4 families and the 'others' group were among the dominant and subdominant families that typified the communities (Table 2). In the first 4 lowbiomass clusters, composed of 117 unique sites with biomass $<500 \mathrm{~kg} \mathrm{ha}^{-1}$, were the Acanthuridae, Labridae, and 'others'. The 3 high-biomass clusters, composed of 121 sites with biomass $>500 \mathrm{~kg} \mathrm{ha}^{-1}$, were also dominated by the Acanthuridae, Labridae, Scaridae, and Lutjanidae. The first 3 low-biomass clusters were largely found in depths $<6 \mathrm{~m}$, while the 4 high-biomass clusters were found in depths $>6 \mathrm{~m}$ (Fig. 2c). Biomass generally increased exponentially along this cluster-ranking gradient while number of species increased asymptotically. A scatterplot of the biomass-species relationship and test for best-fit equations found the asymptotic had better fit than the logistic, Ricker, and linear equation options (Fig. 3). This equation indicates a leveling of $51.7 \pm$ $1.1( \pm \mathrm{SE})$ species at a biomass of $\sim 600 \mathrm{~kg} \mathrm{ha}^{-1}$.

\subsection{Distribution of biomass and communities}

There was some non-random spatial distribution of biomass and number of species, but aggregations 
Table 2. Mean $( \pm \mathrm{SE}$ ) fishable biomass abundance and diversity (Simpson's $D$ ) of the studied fish families in the 7 cluster groups and the average for all clusters. Table ordered by most to least biomass abundance. See Table 1 for cluster abbreviation and names

\begin{tabular}{|c|c|c|c|c|c|c|c|c|}
\hline Family & 1 & 2 & 3 & 4 & 5 & 6 & 7 & Average \\
\hline Acanthuridae & $19.29 \pm 3.0$ & $23.96 \pm 3.43$ & $53.61 \pm 5.46$ & $103.48 \pm 5.10$ & $71.13 \pm 7.29$ & $263.17 \pm 12.81$ & $320.22 \pm 26.17$ & $135.88 \pm 8.55$ \\
\hline Labridae & $31.23 \pm 2.9$ & $33.9 \pm 4.15$ & $52.05 \pm 3.47$ & $74.46 \pm 4.9$ & $87.72 \pm 6.27$ & $67.45 \pm 5.08$ & $103.66 \pm 13.27$ & $71.22 \pm 3.15$ \\
\hline Scaridae & $6.03 \pm 1.52$ & $6.93 \pm 1.37$ & $22.97 \pm 5.00$ & $27.05 \pm 2.73$ & $66.47 \pm 7.19$ & $69.6 \pm 7.28$ & $189.49 \pm 31.64$ & $62.75 \pm 6.50$ \\
\hline Lutjanidae & $2.02 \pm 0.70$ & $8.72 \pm 3.31$ & $3.40 \pm 1.18$ & $10.23 \pm 2.33$ & $28.06 \pm 5.11$ & $36.56 \pm 8.34$ & $200.95 \pm 35.22$ & $45.95 \pm 7.18$ \\
\hline Others & $7.29 \pm 1.32$ & $27.79 \pm 4.70$ & $29.94 \pm 8.87$ & $16.82 \pm 5.37$ & $22.43 \pm 4.20$ & $34.70 \pm 5.55$ & $85.46 \pm 17.33$ & $32.68 \pm 3.63$ \\
\hline Haemulidae & $0.71 \pm 0.40$ & $19.97 \pm 5.14$ & $2.25 \pm 1.14$ & $11.09 \pm 3.38$ & $41.1 \pm 10.73$ & $10.32 \pm 3.98$ & $83.21 \pm 17.02$ & $27.21 \pm 3.97$ \\
\hline Holocentridae & $0.77 \pm 0.33$ & $7.68 \pm 2.80$ & $4.69 \pm 0.99$ & $13.17 \pm 2.85$ & $38.65 \pm 7.13$ & $34.42 \pm 10.71$ & $59.26 \pm 8.01$ & $26.31 \pm 2.86$ \\
\hline Serranidae & $0.15 \pm 0.07$ & $3.78 \pm 1.72$ & $8.06 \pm 4.47$ & $8.93 \pm 1.70$ & $14.58 \pm 3.17$ & $19.17 \pm 3.34$ & $76.82 \pm 12.21$ & $20.88 \pm 2.66$ \\
\hline Balistidae & $0.35 \pm 0.15$ & $0.99 \pm 0.55$ & $4.89 \pm 2.04$ & $5.93 \pm 1.11$ & $17.64 \pm 5.71$ & $21.17 \pm 4.08$ & $75.48 \pm 26.46$ & $20.40 \pm 4.57$ \\
\hline Chaetodontidae & $4.55 \pm 0.83$ & $17.57 \pm 2.05$ & $17.46 \pm 2.57$ & $13.06 \pm 1.17$ & $18.83 \pm 2.49$ & $28.15 \pm 4.47$ & $22.72 \pm 2.34$ & $18.06 \pm 1.08$ \\
\hline Pomacanthidae & $1.01 \pm 0.35$ & $6.83 \pm 3.46$ & $12.18 \pm 2.16$ & $7.30 \pm 0.92$ & $14.09 \pm 2.46$ & $14.97 \pm 2.41$ & $32.49 \pm 5.19$ & $13.62 \pm 1.23$ \\
\hline Siganidae & $2.75 \pm 0.84$ & $2.74 \pm 1.29$ & $2.38 \pm 1.43$ & $3.22 \pm 1.01$ & $10.43 \pm 5.8$ & $4.02 \pm 1.14$ & $53.02 \pm 24.2$ & $12.37 \pm 4.08$ \\
\hline Mullidae & $1.48 \pm 0.24$ & $5.47 \pm 2.60$ & $3.95 \pm 1.00$ & $8.46 \pm 1.43$ & $11.93 \pm 1.77$ & $12.8 \pm 2.33$ & $32.94 \pm 18.57$ & $12.32 \pm 2.99$ \\
\hline Carangidae & $0.00 \pm 0.00$ & $0.30 \pm 0.30$ & $0.18 \pm 0.18$ & $0.05 \pm 0.05$ & $4.36 \pm 2.57$ & $7.45 \pm 2.90$ & $30.67 \pm 14.88$ & $6.83 \pm 2.48$ \\
\hline Pempheridae & $1.45 \pm 0.83$ & $1.24 \pm 0.72$ & $1.78 \pm 1.40$ & $1.87 \pm 0.89$ & $12.95 \pm 6.97$ & $0.72 \pm 0.51$ & $4.47 \pm 1.25$ & $4.23 \pm 1.46$ \\
\hline Aulostomidae & $0.36 \pm 0.22$ & $2.54 \pm 0.98$ & $3.89 \pm 1.32$ & $1.65 \pm 0.42$ & $4.21 \pm 1.18$ & $5.66 \pm 1.63$ & $5.01 \pm 1.41$ & $3.47 \pm 0.45$ \\
\hline Caesionidae & $0.00 \pm 0.00$ & $0.80 \pm 0.79$ & $0.06 \pm 0.06$ & $2.25 \pm 1.07$ & $8.21 \pm 7.57$ & $1.36 \pm 1.00$ & $2.91 \pm 1.36$ & $2.89 \pm 1.57$ \\
\hline Lethrinidae & $0.62 \pm 0.18$ & $1.12 \pm 0.68$ & $1.66 \pm 0.63$ & $0.52 \pm 0.14$ & $3.24 \pm 0.77$ & $1.64 \pm 0.67$ & $5.40 \pm 1.54$ & $2.17 \pm 0.33$ \\
\hline Diodontidae & $0.91 \pm 0.45$ & $0.60 \pm 0.60$ & $0.85 \pm 0.60$ & $3.07 \pm 1.65$ & $0.95 \pm 0.56$ & $1.47 \pm 0.93$ & $4.26 \pm 2.01$ & $1.97 \pm 0.52$ \\
\hline Muraenidae & $0.62 \pm 0.30$ & $0.33 \pm 0.33$ & $0.26 \pm 0.16$ & $0.25 \pm 0.11$ & $1.03 \pm 0.52$ & $1.19 \pm 0.50$ & $0.83 \pm 0.39$ & $0.68 \pm 0.15$ \\
\hline Scorpaenidae & $0.39 \pm 0.19$ & $0.30 \pm 0.23$ & $0.65 \pm 0.51$ & $0.14 \pm 0.05$ & $0.86 \pm 0.48$ & $0.11 \pm 0.06$ & $1.73 \pm 1.13$ & $0.61 \pm 0.21$ \\
\hline Fistularidae & $0.03 \pm 0.02$ & $0.47 \pm 0.30$ & $0.54 \pm 0.37$ & $0.20 \pm 0.12$ & $0.19 \pm 0.13$ & $0.00 \pm 0.00$ & $2.41 \pm 1.23$ & $0.55 \pm 0.20$ \\
\hline Penguipedidae & $0.15 \pm 0.07$ & $0.18 \pm 0.08$ & $0.51 \pm 0.17$ & $0.46 \pm 0.14$ & $0.67 \pm 0.25$ & $0.48 \pm 0.25$ & $0.63 \pm 0.23$ & $0.49 \pm 0.08$ \\
\hline Sphyraenidae & $0.24 \pm 0.24$ & $0.07 \pm 0.07$ & $0.03 \pm 0.02$ & $0.43 \pm 0.30$ & $0.10 \pm 0.07$ & $0.00 \pm 0.00$ & $1.26 \pm 0.69$ & $0.34 \pm 0.13$ \\
\hline Simpson's $D$ & 0.78 & 0.88 & 0.85 & 0.82 & 0.90 & 0.79 & 0.88 & 0.88 \\
\hline
\end{tabular}

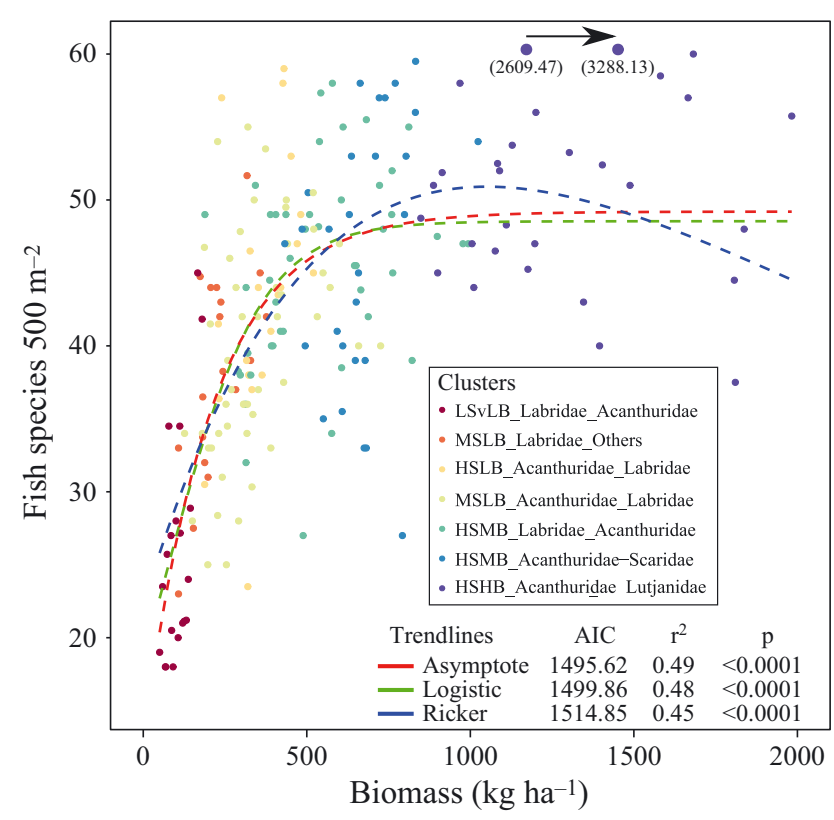

Fig. 3. Relationships between fishable biomass and number of species in 9 families per $500 \mathrm{~m}^{2}$ in the 238 unique study sites. The 7 statistically significant fish communities are distinguished by color and organized from lowest to highest biomass. Details of the fish community cluster groups are described in Table 1. The asymptotic equation had the best fit by Akaike's information criteria (AIC). The larger dots at the top are data points outside the $x$-axis range were generally weak (Moran's $I=0.10-0.34$ ) (Table 3). The family clusters were generally broadly distributed throughout the region with some geographic patterns associated with human influence and fisheries management (Fig. 1, Table 4). Six of the fish communities were mostly found in all management systems while Cluster 7 communities were found more frequently in high-compliance closures. Therefore, Cluster 7 was considered the benchmark community to represent low fishing impacts, albeit within human-influenced seascapes.

The lowest biomass clusters, such as Cluster 1, occurred in most Kenyan fringing reef sites and also near towns and cities along the Tanzania and Mozambique coasts, such as Mtwapa, Tanga, Mtwara, Ibo, and Pemba city (Fig. 1). Moderate biomass clusters were more broadly distributed and often associated with management restrictions or rural areas. Specifically, high biomass was found in high-compliance fisheries closures in Malindi, Watamu, and Mombasa Marine National Parks (MNPs). There were moderate to high biomass clusters in some sparsely populated rural areas of southern Tanzania and Mozambique, including Kilwa, Vamizi, Ibo, and Vilankulos, and north of Lamu in Kenya. There was higher biomass in gear-restricted fishing than low- 
Table 3. Results of Moran's I calculations on fishable biomass and number of fish species testing for spatial autocorrelations that differ from random. Results presented for both site $\times$ time and site-pooled data replication. CCA: canonical correspondence analysis

\begin{tabular}{|c|c|c|c|c|}
\hline Metric & Observed & $\mathrm{SD}$ & Expected & $\mathrm{p}$ \\
\hline \multicolumn{5}{|c|}{ Raw transects, $\mathrm{n}=354$ (biomass), 312 (species) } \\
\hline Fishable biomass $\left(\mathrm{kg} \mathrm{ha}^{-1}\right)$ & 0.24 & 0.04 & -0.004 & $<0.0001$ \\
\hline No. of species per $500 \mathrm{~m}^{2}$ & 0.32 & 0.04 & -0.004 & $<0.0001$ \\
\hline \multicolumn{5}{|c|}{ Pooling transects to sites, $\mathrm{n}=238$ (biomass), 217 (species) } \\
\hline Fishable biomass $\left(\mathrm{kg} \mathrm{ha}^{-1}\right)$ & 0.27 & 0.04 & -0.004 & $<0.0001$ \\
\hline No. of species per $500 \mathrm{~m}^{2}$ & 0.34 & 0.04 & -0.004 & $<0.0001$ \\
\hline $\begin{array}{l}\text { Community structure } \\
\text { (CCA axis } 1 \text { ) }\end{array}$ & 0.20 & 0.04 & -0.004 & $<0.0001$ \\
\hline $\begin{array}{l}\text { Community structure } \\
\text { (CCA axis 2) }\end{array}$ & 0.10 & 0.04 & -0.004 & 0.005 \\
\hline
\end{tabular}

compliance closures. Biomass in exposed sites was higher than in sheltered sites, but the exposed-sheltered classification did not significantly influence the frequencies of the 7 clusters' distributions.

\subsection{Latitudinal distribution of environmental factors}

The latitudinal distribution of environmental factors and fish clusters indicated considerable spread and weak environmental associations with specific cluster groups but more moderate fits to the CCA community axes (Fig. 4). Some variables, such as human gravity, human influence, distance to shore and $50 \mathrm{~m}$ depth (extent of shallow water), and chl $a$ were scattered and lacked clear latitudinal patterns. Other variables, such as mean and median SST and thermal anomaly metrics were unimodal and had peak values $\sim 5^{\circ} \mathrm{S}$. Finally, there were some linear patterns such as light, maximum and minimum SSTs, and TSAs that declined with latitude. In contrast, SST variation and minimum, thermal stress variation and minimum, and bimodality increased with latitude.

\subsection{Relationships between fish communities and environmental variables}

\subsubsection{Fish biomass}

The overall fit of all environmental variables to biomass was moderate to high for the multiple $\left(R^{2}=\right.$ $0.60)$ and step-wise linear procedures $\left(\mathrm{r}^{2}=0.56\right)$. BRT evaluations selected 8 variables that explained $47 \%$ of the variance. Positive associations with biomass (in

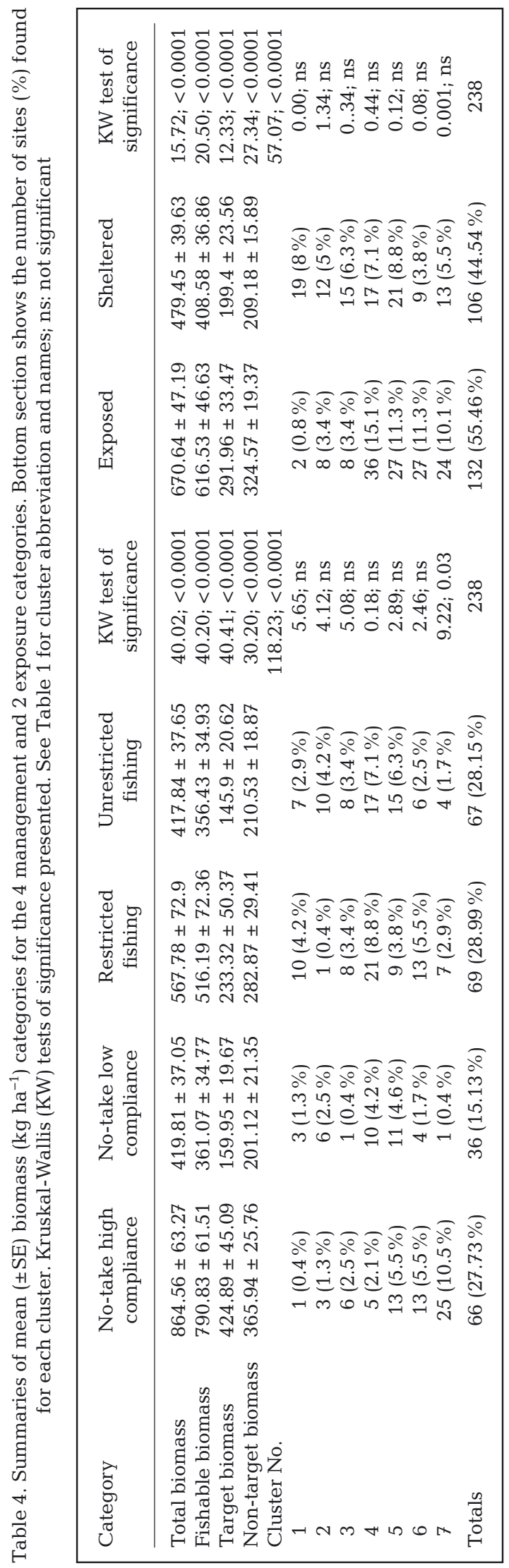




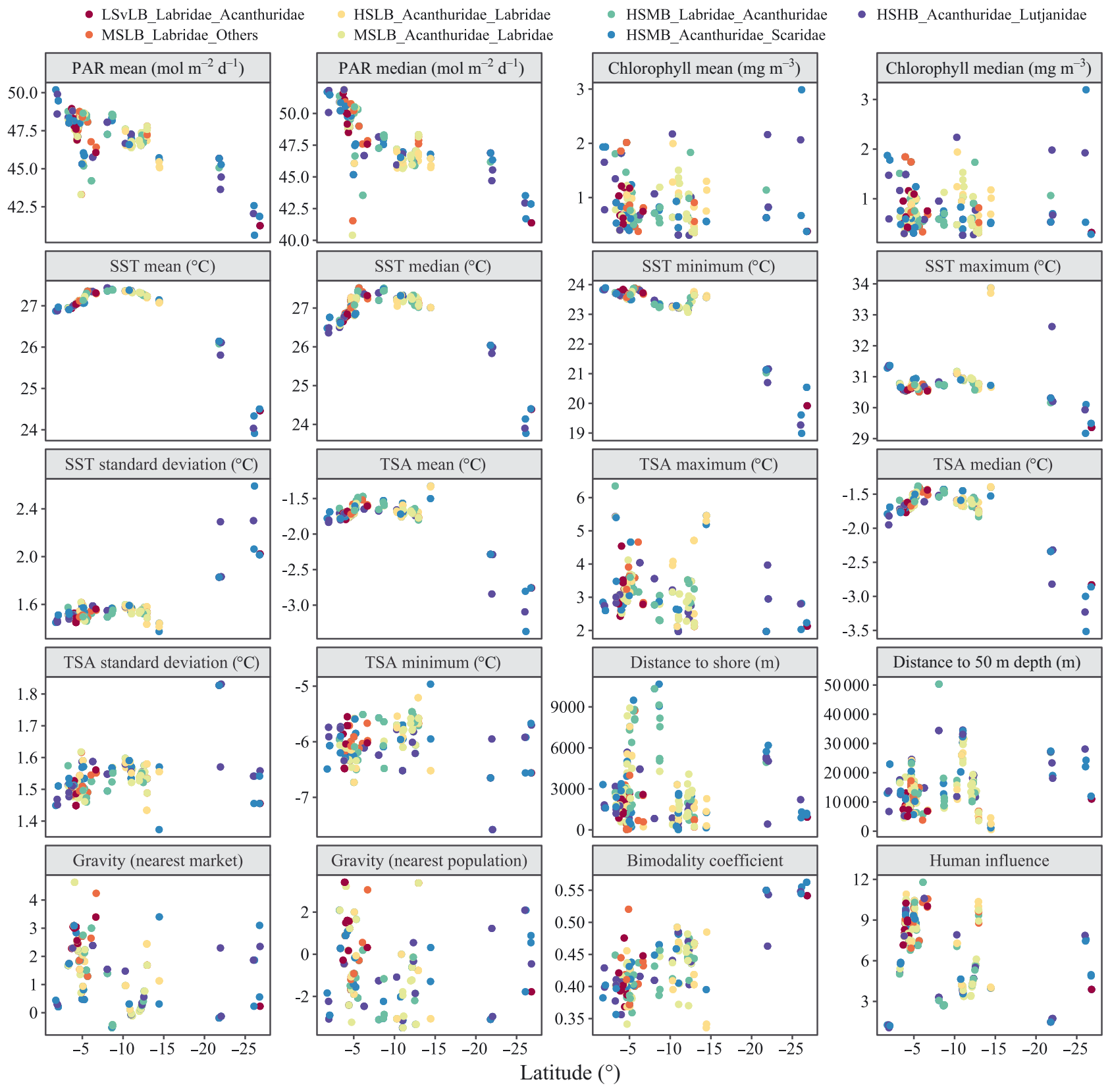

Fig. 4. Relationship between the studied environmental variables, 7 fish communities, and latitude along the East African coast. see Table 1 for description of cluster abbreviations. Gravity is the human population divided by the travel time to either the nearest human population or city market. PAR: photosynthetically active radiation; SST: sea surface temperature; TSA: thermal stress anomaly

order of importance) were the site's distance to a depth of $50 \mathrm{~m}$, depth, soft coral cover, the standard deviation of the TSA, and SST bimodality (Figs. 5 \& S2). Negative associations were human influence and mean SST. The 4 management categories explained a small amount of the variance $(8.6 \%)$. Most of the variance was attributable to high-compliance closure, which was the most different in having high biomass. Some patterns, such as depth and human influence, generally affected the relationships along the continuum of the variable. Others, such as distance to $50 \mathrm{~m}$ depth and soft coral cover, suggest window-specific response. For example, biomass increased abruptly and greatly when the site's distance to $50 \mathrm{~m}$ depth was $>10 \mathrm{~km}$. In contrast, soft coral cover appeared to have its greatest influence at low cover of around $10 \%$ and SST bimodality at intermediate levels. 


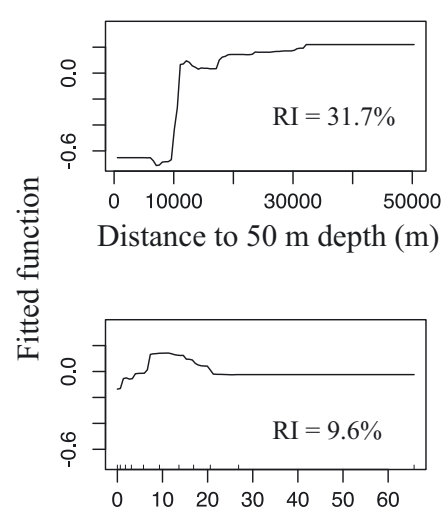

Soft coral cover $(\%)$
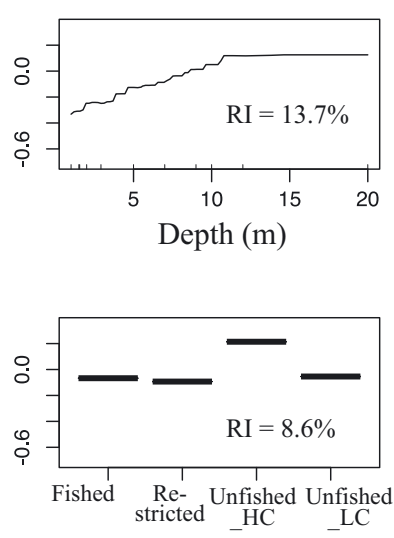

Management
Deviance 0.41 (0.06); Correlation $0.67(0.06)$
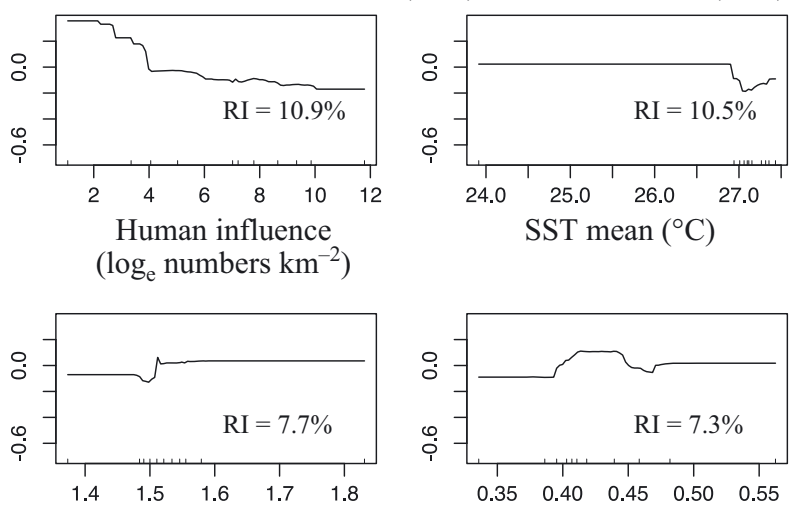

TSA standard deviation $\left({ }^{\circ} \mathrm{C}\right)$

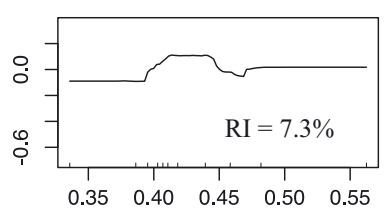

Bimodality coefficient

Fig. 5. Partial dependence plots with the 8 selected environmental variables and fish biomass based on boosted regression tree analysis. This model explains $47 \%$ of the total variance. See Fig. S2 for scatterplot relationships. RI: relative influence;

TSA: thermal stress anomaly; SST: sea surface temperature

\subsubsection{Number of fish species}

Number of fish species also had moderate to high predictive ability for multiple $\left(\mathrm{r}^{2}=0.62\right)$ and stepwise linear regressions $\left(r^{2}=0.50\right)$. However, residuals from the biomass fit had lower explained variance for multiple $\left(\mathrm{r}^{2}=0.19\right)$ and step-wise procedures $\left(\mathrm{r}^{2}=\right.$ 0.07). Testing for unimodal versus linear relationships also found low fits to both models with occasional small improvements for unimodal versus linear models (Figs. 6 \& S3). The improved unimodal fits were with the SST metrics and indicated maximum richness at $\sim 25.9^{\circ} \mathrm{C}$ and with TSAs and its variation. BRT evaluations selected 8 variables that explained $60 \%$ of the variance and found biomass was positive and the strongest variable, explaining $61 \%$ of the model's variance (Figs. $7 \&$ S3). The factors human influence, mean SST, distance to $50 \mathrm{~m}$ depth, TSA minimum, bimodality coefficient, PAR, and TSA standard deviation each explained $<8.5 \%$ of the remaining $49 \%$ of the variance. Very few of these relationships were linear with the exception of a positive relationship with distance to $50 \mathrm{~m}$ depth and a negative relationship with PAR.

\subsubsection{Family associations with environmental variables}

Multivariate CCA axes of the fish family associations with environmental and habitat-benthic cover variables indicated moderate relationships (Fig. 7). Among the environmental variables, a positive relationship was observed for maximum SST while the

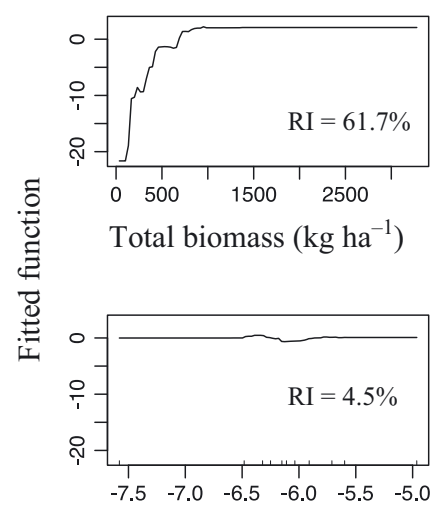

TSA minimum $\left({ }^{\circ} \mathrm{C}\right)$
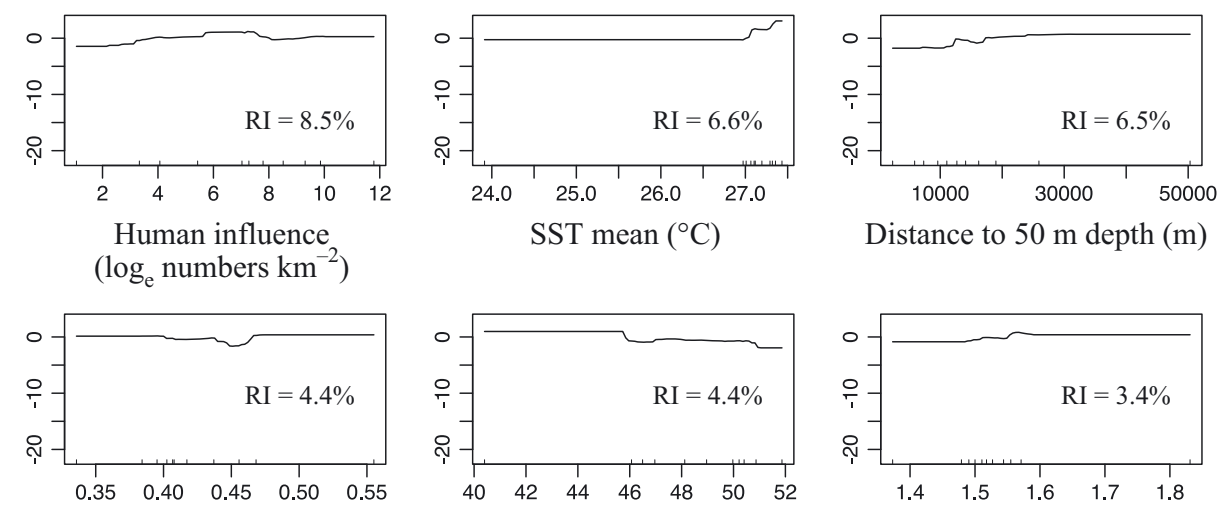

Bimodality coefficient

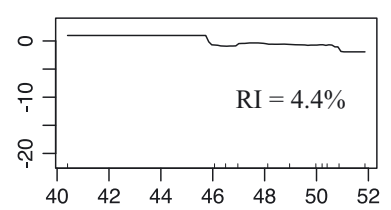

PAR media ( $\left.\mathrm{mol} \mathrm{m}^{2} \mathrm{~d}^{-1}\right)$

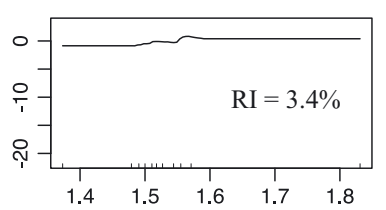

TSA standard deviation $\left({ }^{\circ} \mathrm{C}\right)$

Fig. 6. Partial dependence plots with the 8 selected environmental variables and fish species based on boosted regression tree analysis. The model explains $60 \%$ of the total variance. See Fig. S3 for scatterplot relationships. RI: relative influence; SST: sea surface temperature; TSA: thermal stress anomaly; PAR: photosynthetically active radiation 

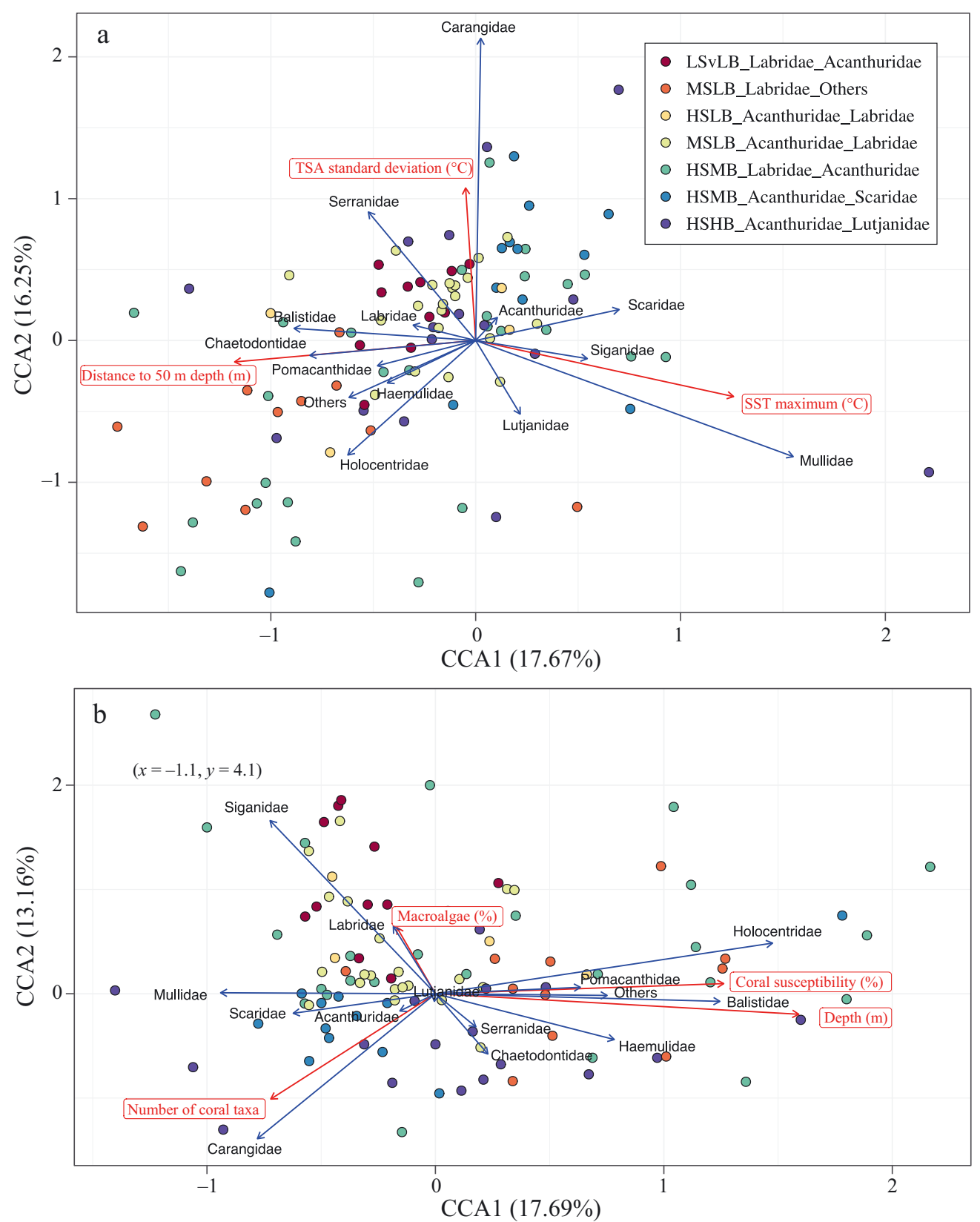

Fig. 7. Canonical correspondence analysis (CCA) associations (blue vectors) with the dominant families and their relationships with statistically significant (a) environmental and (b) habitat variables (red vectors). Sites are differentiated by their association with the 7 cluster groups as in the key; see Table 1 for description of cluster abbreviations

distance to $50 \mathrm{~m}$ depth was negatively associated with the first axis (Fig. 7a). Consequently, Mullidae, Siganidae, and Lutjanidae were more frequently associated with reefs close to deep water with warm but low variation in thermal anomalies. In contrast, the Balistidae, Chaetodontidae, Haemulidae, Holocentridae, and the 'others' were associated with lower maximum SST and more extensive shallow water. The second community axis indicated a positive as- sociation between variation in TSA and the biomass of Serranidae and Carangidae predators. In contrast, the Lutjanidae, Holocentridae, Haemulidae, and Mullidae were associated with less variation in TSA. When evaluating habitat variables, depth, coral community susceptibility to bleaching, number of coral taxa, and percentage of macroalgae were significant (Fig. 7b). Depth and coral community susceptibility to thermal stress were positively associated with Bal- 


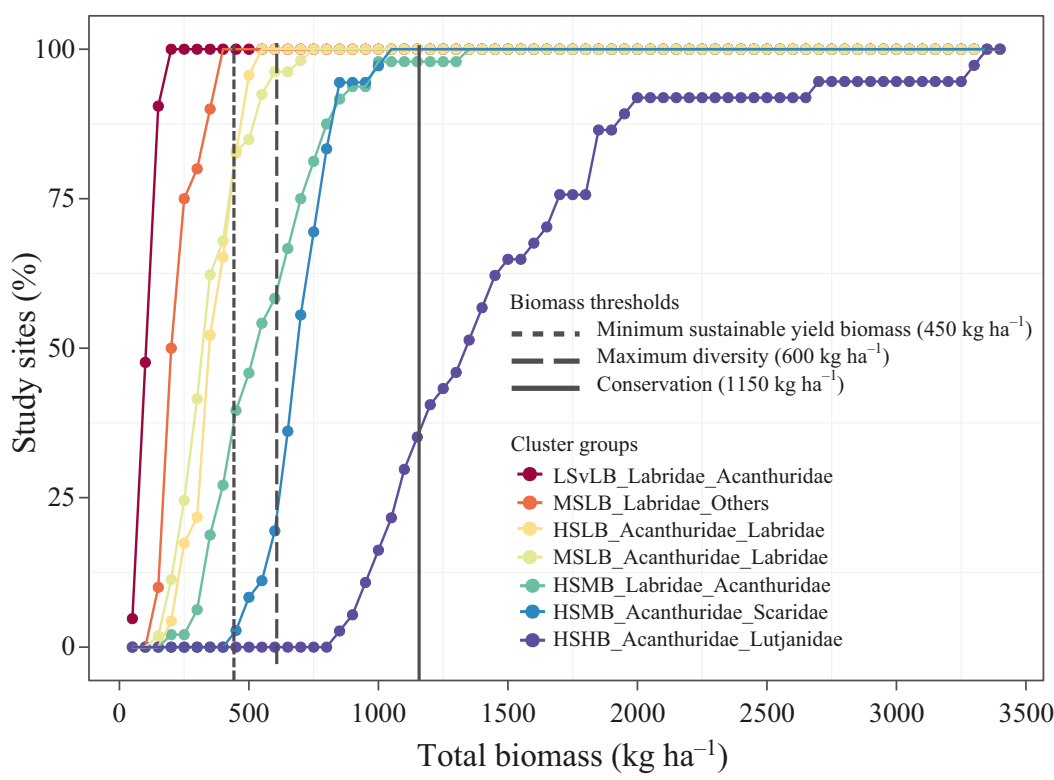

Fig. 8. Cumulative frequencies of fish biomass at 238 sites distributed among the 7 distinct functional ( 24 families) communities in relation to proposed fisheries yield status (minimum biomass for sustainability), biodiversity, and conservation status thresholds (see Section 2.6 and Table 5). Cluster abbreviations as in Table 1

istidae, Pomacanthidae, 'others', Holocentridae, and Haemulidae. The Acanthuridae, Scaridae, and Mullidae were associated with shorter distances to deep water and bleaching-resistant coral communities. The Siganiade and Labridae were positively associated with macroalgae and negatively with number of coral genera. Carangidae, Scaridae, Acanthuridae were the families most associated with high numbers of coral genera.

\subsection{Management and threshold status}

Cumulative frequency plots suggest that about $38 \%$ of the sites were below the biomass required for sustainable yields, while $54 \%$ were below the maximum diversity/trophic structure, and $92 \%$ below the conservation threshold (Fig. 8). The distribution of these sites varied by management (Table 5). Both unrestricted and restricted fishing sites had variable distributions with $41 \%$ below and $<8 \%$ within the maximum sustainable yield (MSY) window. Nevertheless, nearly half the fished sites had biomass $>600 \mathrm{~kg} \mathrm{ha}^{-1}$. Restricted fishing sites were more frequently in the Cluster 7 conservation category than unrestricted fishing (6 vs. 1\%). High- and low-compliance closure sites were distributed similarly, having $<12 \%$ of the sites in the MSY window. Nevertheless, they differed for the other categories-lowcompliance closures had $\sim 40 \%$ of their reefs at $<450 \mathrm{~kg} \mathrm{ha}^{-1}$ but $50 \%$ above $600 \mathrm{~kg} \mathrm{ha}^{-1}$ and no sites above the conservation threshold, whereas highcompliance closures had $28 \%$ of their reefs above the conservation threshold.

The distribution of the 7 communities followed their biomass-diversity distributions with nearly all of Clusters 1 and 2 and $~ 83 \%$ of Clusters 3 and 4

Table 5. Distribution of total biomass among the (top) 4 management categories and (bottom) cluster groups in relation to recommended management thresholds (McClanahan et al. 2016). MSY: maximum sustainable yield; $\mathrm{n}$ : sample sizes. See Table 1 for cluster abbreviation and names

\begin{tabular}{|c|c|c|c|c|c|}
\hline Biomass category & $\mathrm{n}$ & $\begin{array}{l}\text { Less than MSY } \\
\left(<450 \mathrm{kgha}^{-1}\right)\end{array}$ & $\begin{array}{l}\text { MSY (450- } \\
\left.600 \mathrm{~kg} \mathrm{ha}^{-1}\right)\end{array}$ & $\begin{array}{l}\text { High diversity/trophic } \\
\text { structure }\left(>600 \mathrm{~kg} \mathrm{ha}^{-1}\right)\end{array}$ & $\begin{array}{l}\text { Conservation } \\
\left(>1150 \mathrm{~kg} \mathrm{ha}^{-1}\right)\end{array}$ \\
\hline Unrestricted fishing & 67 & $41.1(44)$ & $8.4(9)$ & $49.5(53)$ & $0.9(1)$ \\
\hline Restricted fishing & 69 & $41.0(41)$ & $6.0(6)$ & $47.0(47)$ & $6(6)$ \\
\hline No-take low compliance & 36 & $38.9(21)$ & $11.1(6)$ & $50.0(27)$ & $0.0(0)$ \\
\hline No-take high compliance & 66 & $28.1(18)$ & $7.8(5)$ & $35.9(23)$ & $28.1(18)$ \\
\hline Total \% (n) & $100(238)$ & $38.2(124)$ & $8(26)$ & $46.2(150)$ & $7.7(25)$ \\
\hline \multicolumn{6}{|l|}{ Cluster groups } \\
\hline 1 & 21 & $100(21)$ & $0(0)$ & $0(0)$ & $0(0)$ \\
\hline 2 & 20 & $100(20)$ & $0(0)$ & $0(0)$ & $0(0)$ \\
\hline 3 & 23 & $82.6(19)$ & $17.4(4)$ & $0(0)$ & $0(0)$ \\
\hline 4 & 53 & $83(44)$ & $13.2(7)$ & $3.8(2)$ & $0(0)$ \\
\hline 5 & 48 & $38.8(19)$ & $18.4(9)$ & $40.8(20)$ & $2(1)$ \\
\hline 6 & 36 & $2.8(1)$ & $16.7(6)$ & $80.6(29)$ & $0(0)$ \\
\hline 7 & 37 & $0(0)$ & $0(0)$ & $60.7(37)$ & $39.3(24)$ \\
\hline Total \% (n) & $100(238)$ & $47.1(124)$ & $9.9(26)$ & 33.5 (88) & $9.5(25)$ \\
\hline
\end{tabular}




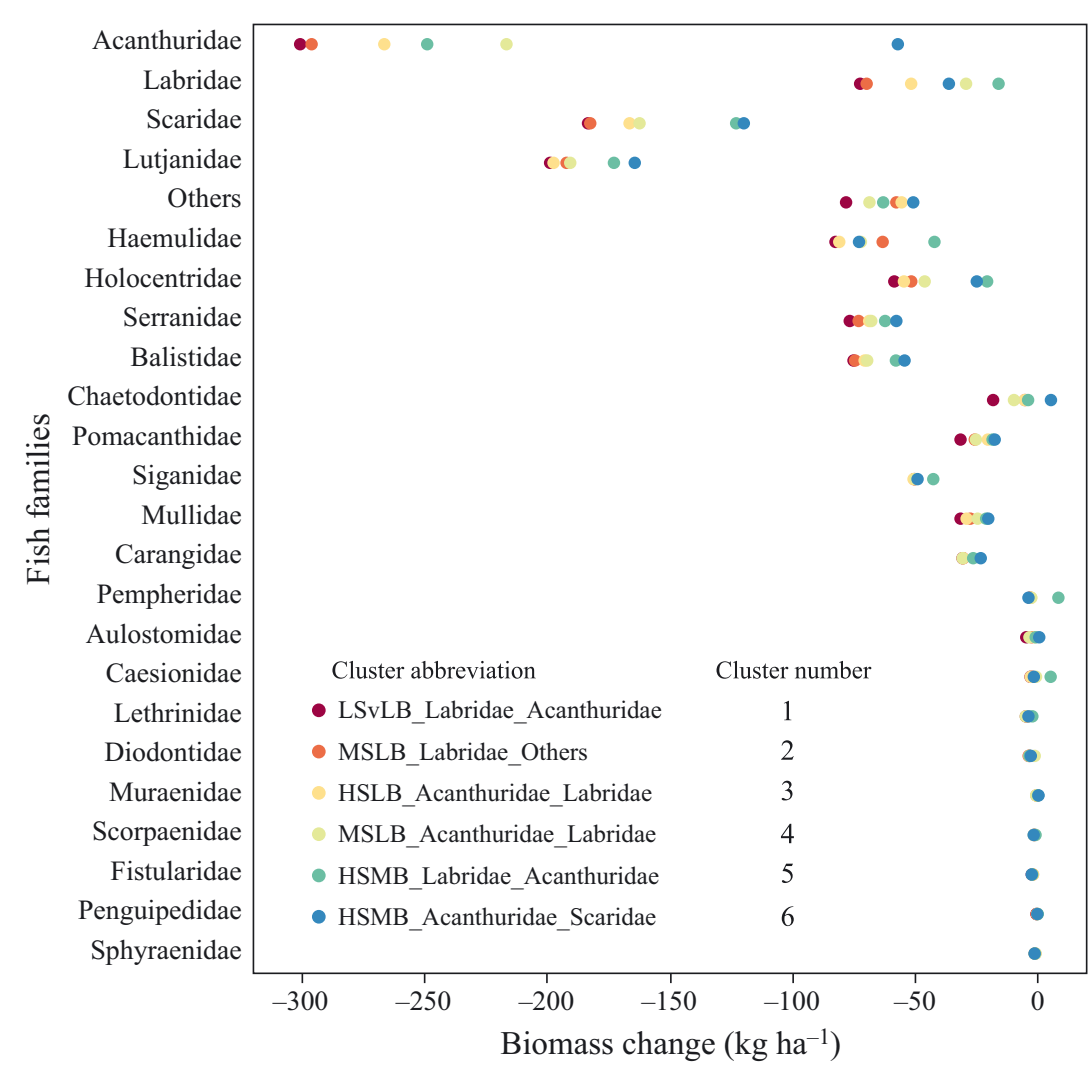

Fig. 9. Differences in fish biomass among the 24 families in Clusters 1-6 relative to the benchmark no-fishing Cluster 7 . Families ordered from highest (top) to lowest (bottom) biomass as distributed in Cluster 7; see Table 1 for description of cluster abbreviations

below the MSY thresholds (Table 5). Cluster 5 had $\sim 70 \%$ of sites within or above MSY but $\sim 60 \%$ below maximum diversity. Cluster 6 had $\sim 90 \%$ of the sites above the MSY and $20 \%$ below maximum diversity. Cluster 7 was unique in having high biomass and all sites above the MSY and maximum diversity as well as $\sim 40 \%$ above the conservation threshold.

Comparing family-level biomass to the proposed no-fishing benchmark (Cluster 7) indicated that only 11 of the 24 families showed depletion from the benchmark (Fig. 9). Therefore, 13 families showed no appreciable change in biomass associated with fishing. Thus, fishing produced the greatest losses among the high-biomass families of the Acanthuridae, Lutjanidae, and Scaridae and more moderate losses among the Haemulidae, Serranidae, Balistidae, 'others', Siganidae, Holocentridae, Carangidae, Mullidae, and Pomacanthidae. Labridae was a unique family in having high biomass but more modest depletion. The family-level sequence of depletion follows the overall decline in biomass from Clusters 6 to 1.

\section{DISCUSSION}

My family-level evaluations indicated 7 distinct fish communities that were likely to represent core aspects of the reef's ecological function. Family biomass (which is driven largely by body size) and gross life histories and functions should frequently be aligned in terms of the movement of energy and materials (Bellwood et al. 2019, McClanahan 2019). The communities were widely distributed and appeared to be weakly associated with exposure and even some management systems all communities being present in most exposure and management systems. Nevertheless, Cluster 7 was unique and therefore established as a 'no-fishing' benchmark because it's biomass was consistently above the proposed MSY and conservation thresholds. Thus, with the exception of the Labridae, Clusters 1-6 represented a sequential depletion of the target fish families proportional to the biomass of the benchmark families.

The biomass and associated ecologies along this coast were largely driven by 4 dominant families, 2 herbivore groups (the Acanthuridae and Scaridae) and 2 carnivores (Labridae and Lutjanidae), that were distinguished by their biomass and depth associations. Depth and fishing effort were probably related, and therefore the Scaridae and Lutjanidae found refuge via depth, exposure, fishing restrictions, and people's access to the site. Significant populations of the large-bodied Scaridae and Lutjanidae families were critical to reaching the highest biomass levels. Haemulidae, Holocentriade, Serranidae, and Balistidae were among the other important human-impacted subdominant predator families. The Labridae appeared most resistant to biomass depletion, possibly through their fusiform body shapes and increased ability to escape capture, or due to higher recruitment and productivity (Brandl et al. 2019).

This study aligns with some findings in the adjacent Madagascar ecoregion that showed weak spatial structure in fish families over broad scales but a moderate influence of depth and possibly patchy influence of people along with benthic production and composition (McClanahan \& Jadot 2017). Madagascar reefs are mostly on the western leeward side 
of the island and exposure was therefore not evaluated. Here, on the eastern and seaward side of the African continent, I found that sheltered areas had lower biomass than exposed sites, likely due to differences in fishing access created by seasonal exposure to waves and currents during the winter southeast monsoons. Rough seas impede fishing effort and allow safe access to exposed sites mostly during the calm summer or northeast monsoon season (Thoya \& Daw 2019). Similarly, some of the geographic gradients are likely to reflect the distribution of people and urban-rural gradients interacting with the extent of shallow water and management restrictions (Cinner et al. 2016). Higher spatial structure reported among fish communities at finer taxonomic levels does not necessarily conflict with the weaker structure found in my family-level analysis (Parravicini et al. 2014, Samoilys et al. 2019).

\subsection{Fish biomass and associations}

Biomass was the primary driver of the state and organization of these communities and it was also moderately associated with a number of environmental variables. Here, depth, high-compliance closures, and human influence were associated with biomass, as would be expected (Tyler et al. 2009, McClanahan \& Graham 2015). Distance to deep water was, however, the most influential variable. It has seldom been evaluated - possibly due to a strong non-linear association that is difficult to detect with linear models. The importance of this factor suggests that extensive shallow benthos within $10 \mathrm{~km}$ of a sites is an important contributor to reef fish biomass. Human influence was slightly less important than this metric and suggests that large-scale benthic production can be very important. This finding supports the proposals that coral reef fish feed on and utilize benthic energy more broadly than just the carbonate reef (Khan et al. 2017). Shallow water provides more benthic production than the pelagic production associated with deep water adjacent to some reefs (Polovina 1984). This appeared to have positive responses for some nocturnal and migrating families of the Haemulidae and Holoentridae but also more site-attached taxa in the Pomacanthidae, Chaetodontidae, and Balisidae. Thus, the mechanisms influencing biomass may include a mixture of daily migrations to access benthic production off the reef or perhaps through increased detritus and detritivores on the reef.

Pelagic production can contribute to fish productivity and sometimes to the biomass of planktivores and 'others' groups (Williams et al. 2015, Morais \& Bellwood 2019). Nevertheless, here I found no association with chl a concentrations and fish biomass. Variation in chl $a$ along the coastline was small and most sampled reefs were not associated with oceanic island-induced upwelling that can influence biomass, particularly among planktivores (Williams et al. 2015, Gove et al. 2016). This may also be reflected in the low and patchy biomass of some important reef planktivores (such as caesionids) in this region (Table 2). Biomass is, however, not always a good indicator of productivity, especially when comparing taxa with large differences in body sizes (Brandl et al. 2019).

Distinguishing pelagic from benthic production and consumers and possibly island-continental and upand down-welling reefs should be important when evaluating sources of production and fish biomass. Here, the continental location and dominance of benthic-attached herbivores and carnivores suggest benthic rather than pelagic production influenced productivity via, in part, the extent of shallow water. Given the lack of studies examining the effect of distance to depth, its relationships to benthic and pelagic production requires more examination. Bathymetric slope is a similar proxy that has been used as a benthic/pelagic production proxy in some Pacific Islands. For example, Yeager et al. (2017) found that biomassnormalized fish trait diversity was positively associated with productivity metrics but negatively with increasing bathymetric slope, supporting the proposal that biomass and trait diversity are associated with large-scale benthic production that declines as bathymetric slope and the oceanic influences increase. I also observed a weak increase in number of species with the extent of shallow water. Therefore, these converging patterns on trait and species diversity require further investigation.

SST associations were weak and complicated in terms of the association-causation relationships in that it influenced some but not all families. Some infrequently evaluated variables such as the mean variance of TSA and bimodality had similar influences on total biomass than mean SST. Mean SST had a weak and variable effect at the highest ends of SST. In contrast, TSA variance and bimodality appeared to have weak unimodal influences. Some of these impacts may be taxa-specific, as warmer but less anomalous SST were weakly associated with higher dominance of Mullidae, Scaridae, Lutjanidae, and Siganidae and fewer Serranidae, Balistidae, and Labridae. Low variation in TSAs were found in the warmer water and therefore associated 
with these same warm-water families and communities, and vice versa. These findings indicate the complicated nature of the interactions between largescale oceanographic changes, interactions with the nearshore bathymetry, and benthic and fish community composition.

Biomass depletion by fishing was most evident when evaluating the target versus non-target nature of the biomass. For example, when comparing highcompliance closures with fished reefs, fishable biomass declined from 790 to $356 \mathrm{~kg} \mathrm{ha}^{-1}$, whereas nontarget biomass declined by a smaller margin, from 364 to $210 \mathrm{~kg} \mathrm{ha}^{-1}$. This is also apparent when evaluating the biomass distributions of the families and when comparing global remote unfished seascapes $\left(\sim 1900 \mathrm{~kg} \mathrm{ha}^{-1}\right)$ with old closures in fished seascapes $\left(\sim 750 \mathrm{~kg} \mathrm{ha}^{-1}\right)$ (McClanahan et al. 2019). Benchmark sites in East Africa aligned well with global closure biomass estimates but very few (if any) sites had biomass numbers approaching remote uninhabited seascapes. Thus, it is likely that there are very few (or no) unfished seascapes along the East African coastline.

\subsection{Number of species}

Number of species was closely associated with biomass and therefore the other selected environmental variables were weakly associated with this metric. Consequently, there was a tight linkage between biomass and richness that challenges efforts to find causative relationships with environmental variables (McClanahan 2015). Numbers of taxa showed a weak peak value at around $25.9^{\circ} \mathrm{C}$ along this coastline that was likely driven by biomass and habitat. When habitat and biomass were statistically eliminated there was little evidence for environmental or geographic associations with richness (McClanahan 2015). Moreover, the BRT analysis selected 7 nonbiomass variables that were weakly associated with local diversity but unclear in terms of causation. For example, the relationship with distance to $50 \mathrm{~m}$ depth was positive while PAR was negative and yet both factors should increase productivity. The other variables were often unimodal or influential within a specific window of the predictor variable, suggesting some weak optimizing effects of species richness. Given the weak relationships and non-independence from biomass, most local species richness patterns will require further investigation to better understand causation. I consider taxonomic richness to be best explained by evolutionary and biogeographical processes and associated niche partitioning-packing mechanisms (Barber \& Meyer 2015). Thus, protecting biodiversity and associated services should be best served by maintaining spatially diverse shallow coral habitats and biomass rather than focusing management efforts on protecting isolated locations with high local richness (Mellin et al. 2014, Lefcheck et al. 2019).

\subsection{Thresholds and status}

Reef fish communities were broadly distributed in East Africa and are currently largely driven by biomass, large-scale production, and fishing access. Proposed management goals based on the suggested MSY, maximum diversity/trophic ecologies, and conservation status thresholds provide insight into the region's status and management needs. A small proportion $(8 \%)$ of the studied sites achieved the proposed conservation status and were largely restricted to the region's $<5 \%$ nearshore area in high-compliance closures (Wells et al. 2007). About $54 \%$ of the studied sites were not achieving maximum diversity and $38 \%$ were below sustainable yield limit. These frequencies are optimistic given that my study sites were not randomly chosen, but rather reflected my interest in evaluating the outcomes of restrictive management (McClanahan et al. 2015).

These findings reflect a social-ecological system below the limits of production, where biodiversity and associated ecologies are being compromised and conservation is insufficient to meet common stock and protected-area recommendations for sustainability (Worm et al. 2009, Gaines et al. 2010). A number of dominant families, such as Scaridae and Lutjanidae, and subdominant families, such as the Haemulidae, Holocentriade, Serranidae, and Balistidae were underrepresented in most low-biomass-high fishing effort sites. Some of the rare species in these families have been identified as threatened with local extirpation (Buckley et al. 2019). Some taxa, such as species in the Balistidae, play important ecological roles that influence benthic composition and production (McClanahan \& Muthiga 2016a,b, Graham et al. 2017). Thus, taxa-specific management would benefit from a focus on these families and raising their biomass, productivity, and associated ecological services.

Evaluating regional status requires accounting for the non-random sampling of this study. Restrictive management and its feasibility have low coverage and uneven distributions in the region (Jones et al. 2018). Therefore, actual regional status will differ from the frequencies reported here, which are biased 
towards more frequent sampling in closures and restricted fishing sites relative to their actual frequency in the region. This spatial bias is confirmed by a modeling study that used empirical data to extrapolate and estimate the whole reef system status and recovery needs (McClanahan et al. 2016). This method found that the percentage of total reef area with biomass above the conservation threshold was $<1 \%$ in Kenya, Tanzania, and Mozambique. Further, the model estimated that $71 \%$ of these countries had biomass $<450 \mathrm{~kg} \mathrm{ha}^{-1}$ and only $6.4 \%$ had levels $>600 \mathrm{~kg} \mathrm{ha}^{-1}$. Thus, non-random sampling that selects sites with greater management restrictions, that are deeper, more exposed, or more remote than their actual frequency will overestimate biomass and status. Nevertheless, if stricter management were more widely implemented, biomass could recover to more sustainable levels and contribute to reducing the region's food insecurity.

Acknowledgements. The Wildlife Conservation Society supported this work through grants from the John D. and Catherine T. MacArthur Foundation (Grant No. G-1511-150370), Tiffany \& Co. Foundation, and the Western Indian Ocean Marine Science Association's Marine Science for Management Program. I am grateful for the field and logistic assistance of H. Kalombo, A. Kamukuru, J. Maina, I. MarquisDaSilva, N. Muthiga, M. J. Rodrigues, and J. Kosgei and M. Azali for producing statistics, tables, and graphs. Permissions and logistic support were provided by Faculty of Aquatic Sciences, University of Dar es Salaam, Eduardo Mondline University, Kenya's Office of Science and Technology, World Wide Fund for Nature (WWF-Mozambique), and Wildlife Conservation Society (WCS) country offices in Tanzania and Mozambique.

\section{LITERATURE CITED}

Barber PH, Meyer CP (2015) Pluralism explains diversity in the Coral Triangle. In: Mora C (ed) Ecology of fishes on coral reefs. Cambridge University Press, Cambridge, p 258-263

Bellwood DR, Streit RP, Brandl SJ, Tebbett SB (2019) The meaning of the term 'function' in ecology: a coral reef perspective. Funct Ecol 33:948-961

Brandl SJ, Tornabene L, Goatley CHR, Casey JM and others (2019) Demographic dynamics of the smallest marine vertebrates fuel coral-reef ecosystem functioning. Science 364:1189-1192

* Brewer TD, Cinner JE, Green A, Pressey RL (2013) Effects of human population density and proximity to markets on coral reef fishes vulnerable to extinction by fishing. Conserv Biol 27:443-452

Buckley SM, McClanahan TR, Morales EMQ, Mwakha V, Nyanapah J, Otwoma LM, Pandolfi JM (2019) Identifying species threatened with local extinction in tropical reef fisheries using historical reconstruction of species occurrence. PLOS ONE 14:e0211224
Cinner JE, Huchery C, MacNeil MA, Graham NAJ and others (2016) Bright spots among the world's coral reefs. Nature 535:416-419

Cinner JE, Maire E, Huchery C, MacNeil MA and others (2018) Gravity of human impacts mediates coral reef conservation gains. Proc Natl Acad Sci USA 115:E6116-E6125

KClarke SE, Burnett KM, Miller DJ (2008) Modeling streams and hydrogeomorphic attributes in Oregon from digital and field data. J Am Water Resour Assoc 44:459-477

* Clauson-Kaas S, Richardson K, Rahbek C, Holt BG (2017) Species specific environmental preferences associated with a hump shaped diversity/temperature relationship across tropical marine fish assemblages. J Biogeogr 44: 2343-2353

Elith J, Leathwick JR, Hastie T (2008) A working guide to boosted regression trees. J Anim Ecol 77:802-813

* Gaines SD, White C, Carr MH, Palumbi SR (2010) Designing marine reserve networks for both conservation and fisheries management. Proc Natl Acad Sci USA 107: 18286-18293

*Gorospe KD, Donahue MJ, Heenan A, Gove JM, Williams ID, Brainard RE (2018) Local biomass baselines and the recovery potential for Hawaiian coral reef fish communities. Front Mar Sci 5:162

Gove JM, McManus MA, Neuheimer AB, Polovina JJ and others (2016) Near-island biological hotspots in barren ocean basins. Nat Commun 7:10581

*Graham NAJ, McClanahan TR, MacNeil MA, Wilson SK, Cinner JE, Huchery C, Holmes TH (2017) Human disruption of coral reef trophic structure. Curr Biol 27:231-236

*Hicks CC (2011) How do we value our reefs? Risks and tradeoffs across scales in 'biomass-based' economies. Coast Manage 39:358-376

* Jones KR, Maina JM, Kark S, McClanahan TR, Klein CJ, Beger M (2018) Incorporating feasibility and collaboration into large-scale planning for regional recovery of coral reef fisheries. Mar Ecol Prog Ser 604:211-222

KKhan JA, Goatley CHR, Brandl SJ, Tebbett SB, Bellwood DR (2017) Shelter use by large reef fishes: long-term occupancy and the impacts of disturbance. Coral Reefs 36 : 1123-1132

* Lefcheck JS, Innes-Gold AA, Brandl SJ, Steneck RS, Torres RE, Rasher DB (2019) Tropical fish diversity enhances coral reef functioning across multiple scales. Sci Adv 5: eaav6420

Legendre P, Legendre LC (1998) Numerical ecology. Elsevier, New York, NY

MacNeil MA, Graham NAJ, Cinner JE, Wilson SK and others (2015) Recovery potential of the world's coral reef fishes. Nature 520:341-344

* Maire E, Cinner J, Velez L, Huchery C and others (2016) How accessible are coral reefs to people? A global assessment based on travel time. Ecol Lett 19:351-360

*McClanahan TR (2015) Biogeography versus resource management: How do they compare when prioritizing the management of coral reef fishes in the southwestern Indian Ocean? J Biogeogr 42:2414-2426

McClanahan TR (2018a) Community biomass and life history benchmarks for coral reef fisheries. Fish Fish 19: 471-488

* McClanahan TR (2018b) Multicriteria estimate of coral reef fishery sustainability. Fish Fish 19:807-820

* McClanahan TR (2019) Coral reef fish community life history traits as potential global indicators of ecological and fisheries status. Ecol Indic 96:133-145 
McClanahan TR, Graham NAJ (2015) Marine reserve recovery rates towards a baseline are slower for reef fish community life histories than biomass. Proc R Soc B 282: 20151938

*McClanahan TR, Jadot C (2017) Managing coral reef fish community biomass is a priority for biodiversity conservation in Madagascar. Mar Ecol Prog Ser 580:169-190

* McClanahan TR, Kaunda-Arara B (1996) Fishery recovery in a coral reef marine park and its effect on the adjacent fishery. Conserv Biol 10:1187-1199

McClanahan TR, Muthiga NA (2016a) Geographic extent and variation of a coral reef trophic cascade. Ecology 97 : 1862-1872

* McClanahan TR, Muthiga NA (2016b) Similar impacts of fishing and environmental stress on calcifying organisms in Indian Ocean coral reefs. Mar Ecol Prog Ser 560: 87-103

McClanahan TR, Ateweberhan M, Graham NAJ, Wilson SK, Sebastián CR, Guillaume MMM, Bruggemann JH (2007) Western Indian Ocean coral communities: bleaching responses and susceptibility to extinction. Mar Ecol Prog Ser 337:1-13

McClanahan TR, Graham NAJ, Wilson SK, Letourneur Y, Fisher R (2009) Effects of fisheries closure size, age, and history of compliance on coral reef fish communities in the western Indian Ocean. Mar Ecol Prog Ser 396:99-109

* McClanahan TR, Graham NAJ, MacNeil MA, Muthiga NA, Cinner JE, Bruggemann JH, Wilson SK (2011) Critical thresholds and tangible targets for ecosystem-based management of coral reef fisheries. Proc Natl Acad Sci USA 108:17230-17233

* McClanahan TR, Graham NAJ, MacNeil MA, Cinner JE (2015) Biomass based targets and the management of multispecies coral reef fisheries. Conserv Biol 29:409-417

McClanahan TR, Maina JM, Graham NAJ, Jones KR (2016) Modeling reef fish biomass, recovery potential, and management priorities in the western Indian Ocean. PLOS ONE 11:e0154585

McClanahan TR, Schroeder RE, Friedlander AM, Vigliola L and others (2019) Global baselines and benchmarks for fish biomass: comparing remote and fisheries closures. Mar Ecol Prog Ser 612:167-192

Mellin C, Bradshaw CJA, Fordham DA, Caley MJ (2014) Strong but opposing $\beta$-diversity-stability relationships in coral reef fish communities. Proc R Soc B 281:20131993

Mellin C, Mouillot D, Kulbicki M, McClanahan TR and others (2016) Humans and seasonal climate variability threaten large-bodied coral reef fish with small ranges. Nat Commun 7:10491

Morais RA, Bellwood DR (2019) Pelagic subsidies underpin fish productivity on a degraded coral reef. Curr Biol 29: 1521-1527

Mouillot D, Parravicini V, Bellwood DR, Leprieur F and others (2016) Global marine protected areas do not secure the evolutionary history of tropical corals and fishes. Nat Commun 7:10359

Editorial responsibility: Stephen Wing, Dunedin, New Zealand
Pante E, Simon-Bouhet B, Irisson JO, Simon-Bouhet MB, Imports DBI (2018) Package 'marmap'. R package version 1.0.2. https://cran.r-project.org/package=marmap

* Parravicini V, Kulbicki M, Bellwood DR, Friedlander AM and others (2013) Global patterns and predictors of tropical reef fish species richness. Ecography 36:1254-1262

*Parravicini V, Villéger S, McClanahan TR, Arias González JE and others (2014) Global mismatch between species richness and vulnerability of reef fish assemblages. Ecol Lett 17:1101-1110

* Pellissier L, Leprieur F, Parravicini V, Cowman PF and others (2014) Quaternary coral reef refugia preserved fish diversity. Science 344:1016-1019

Polovina JJ (1984) Model of a coral reef ecosystem. Coral Reefs 3:1-11

* Pratchett MS, Hoey AS, Wilson SK (2014) Reef degradation and the loss of critical ecosystem goods and services provided by coral reef fishes. Curr Opin Environ Sustain 7 : $37-43$

Robinson JPW, Wilson SK, Robinson J, Gerry C and others (2019) Productive instability of coral reef fisheries after climate-driven regime shifts. Nat Ecol Evol 3:183-190

Samoilys MA, Halford A, Osuka K (2019) Disentangling drivers of the abundance of coral reef fishes in the Western Indian Ocean. Ecol Evol 9:4149-4167

Spalding MD, Fox HE, Allen GR, Davidson N and others (2007) Marine ecoregions of the world: a bioregionalization of coastal and shelf areas. Bioscience 57:573-583

* Thibaut LM, Connolly SR (2013) Understanding diversitystability relationships: towards a unified model of portfolio effects. Ecol Lett 16:140-150

* Thoya P, Daw TM (2019) Effects of assets and weather on small-scale coastal fishers' access to space, catches and profits. Fish Res 212:146-153

Tyler EHM, Speight MR, Henderson P, Manica A (2009) Evidence for a depth refuge effect in artisanal coral reef fisheries. Biol Conserv 142:652-667

WWells S, Burgess N, Ngusaru A (2007) Towards the 2012 marine protected area targets in Eastern Africa. Ocean Coast Manage 50:67-83

*Westneat MW, Alfaro ME, Wainwright PC, Bellwood DR and others (2005) Local phylogenetic divergence and global evolutionary convergence of skull function in reef fishes of the family Labridae. Proc R Soc B 272:993-1000

Williams GJ, Graham NAJ (2019) Rethinking coral reef functional futures. Funct Ecol 33:942-947

Williams ID, Baum JK, Heenan A, Hanson KM, Nadon MO, Brainard RE (2015) Human, oceanographic and habitat drivers of central and western Pacific coral reef fish assemblages. PLOS ONE 10:e0120516

*Worm B, Hilborn R, Baum JK, Branch TA and others (2009) Rebuilding global fisheries. Science 325:578-585

Yeager LA, Deith MCM, McPherson JM, Williams ID, Baum JK (2017) Scale dependence of environmental controls on the functional diversity of coral reef fish communities. Glob Ecol Biogeogr 26:1177-1189

Submitted: June 24, 2019; Accepted: October 7, 2019 Proofs received from author(s): December 3, 2019 